\title{
COMUNICAÇÃO
}

\section{CARACTERÍSTICA E RENDIMENTO DO FEIJÃO-VAGEM EM FUNÇÃO DE DOSES E FORMAS DE APLICAÇÃO DE NITROGÊNIO ${ }^{1}$}

\author{
ADEMAR PEREIRA DE OLIVEIRA ${ }^{2}$ \\ JOSÉ TAVARES SOBRINHO \\ ADAILSON PEREIRA DE SOUZA ${ }^{4}$
}

\begin{abstract}
RESUMO - Com o objetivo de avaliar doses e formas de aplicação de nitrogênio na cultura do feijão-vagem, cultivar Macarrão Trepador, instalou-se um experimento em condições de campo no período de abril a agosto de 2000, no Centro de Ciências Agrárias da Universidade Federal da Paraíba. O delineamento experimental empregado foi o de blocos casualizados, em esquema fatorial $6 \times 2+1$, compreendendo seis doses de nitrogênio $(0,20,40,60,80$ e $100 \mathrm{~kg} / \mathrm{ha})$, duas formas de aplicação (solo e via foliar) e um tratamentotestemunha (sem adubação), em quatro repetições. Utilizaram-se parcelas úteis com 20 plantas, espaçadas de $1,00 \times 0,50 \mathrm{~m}$. Pelos resultados, constatou-se efeito significativo das doses e formas de aplicação de nitrogênio
\end{abstract}

sobre a precocidade e a produtividade do feijão-vagem, e sobre o teor de fibra nas vagens. As doses de 21,31 $\mathrm{kg} / \mathrm{ha}$ e $19,55 \mathrm{~kg} / \mathrm{ha}$ de nitrogênio aplicadas, respectivamente na folha e no solo, proporcionaram plantas mais precoces, embora com início de floração mais tardio do que a testemunha. A produtividade de vagens atingiu valores máximos estimados de 29 e 28 t/ha nas doses de 54 e $55 \mathrm{~kg} / \mathrm{ha}$ de nitrogênio aplicados no solo e via foliar, respectivamente. A dose de $44 \mathrm{~kg} / \mathrm{ha}$ de nitrogênio aplicado no solo proporcionou o mais baixo percentual de fibra nas vagens $(1,0 \%)$. As doses mais econômicas de nitrogênio aplicadas no solo e via foliar foram de 53,7 e $54,4 \mathrm{~kg} / \mathrm{ha}$, resultando num rendimento estimado de 28,8 e 27,9 t/ha de vagens, respectivamente.

TERMOS PARA INDEXAÇÃO: Phaseolus vulgaris, vagem, adubação nitrogenada, rendimento, fibra.

\section{CHARACTERISTICS AND YIELD OF SNAP-BEAN IN FUNCTION OF LEVELS AND APPLICATION FORMS OF NITROGEN}

\begin{abstract}
With the objective of evaluating levels and sources of organic matter in the culture of the snapbean, Macarrão Trepador cultivar, it was set an experiment in field conditions, from April to August 2000, in the Center of Agricultural Sciences at the Federal University of Paraíba, Brazil. The experimental design was randomized blocks, in a factorial scheme 6 $\times 2+1$, with four levels of $\mathrm{N}(0,20,40,60,80$, and $100 \mathrm{~kg} / \mathrm{ha}$ ), two application forms (soil and foliar) and a check (without fertilization), with four replications. It were used plots with 20 plants, spaced $1 \times 0.5 \mathrm{~m}$. The results showed significant effect of $\mathrm{N}$ levels and forms
\end{abstract}

INDEX TERMS: Phaseolus vulgaris, pod, nitrogen fertilization, yield, fiber.

\footnotetext{
1. Parte da dissertação apresentada ao Programa de Pós-Graduação em Agronomia do CCA-UFPB, pelo segundo autor.

2. Professor Dr., Departamento de Fitotecnia do CCA-UFPB. Bolsista CNPq.

3. Engenheiro Agrônomo, D.Sc., Secretário de Agricultura do município de Areia-PB.

4. Professor Dr., Departamento de Solos e Engenharia Rural do CCA-UFPB do CCA-UFPB.
} 
A vagem ou feijão-vagem pode ser caracterizado como uma hortaliça cujo grupo de variedades, adaptado à produção e de consumo, tem importância mundial (Filgueira, 2000). Sua exploração comercial visa ao aproveitamento direto das vagens ainda tenras que são consumidas "in natura”. ou industrializadas (Tessarioli Neto \& Groppo, 1992; Athanásio, 1993).

O Brasil produz quase todo adubo nitrogenado consumido em sua agricultura. Porém, entre os fertilizantes, o nitrogênio é o mais caro em termos de energia necessária para produzi-la. Além desse aspecto, contribui para elevar os custos agrícolas decorrentes de suas perdas devido a sua dinâmica no solo. Desse modo, conhecer as exigências nutricionais das plantas e associálas à aplicação de quantidades adequadas de fertilizantes é uma das estratégias para usar o nitrogênio de modo mais eficiente (Malavolta, 1981).

O nitrogênio é o segundo nutriente mais exigido pelas hortaliças (Filgueira, 2000). Seu fornecimento via adubação funciona como complementação à capacidade de seu suprimento nos solos, a partir da mineralização de seus estoques de matéria orgânica, geralmente baixas em relação às necessidades das plantas (Malavolta, 1990).

Nas hortaliças, o nitrogênio desempenha papel fundamental no crescimento e no rendimento dos produtos colhidos. Na alface, a aplicação de doses elevadas proporcionaram maior peso fresco e maiores acúmulos de macronutrientes nas folhas, independente da fonte (Alvarenga et al., 2000). No alho, além de aumentar a área foliar, aumenta peso médio, produção total e comercial de bulbos (Resende \& Souza., 2000). Na batatinha, eleva a produtividade e peso médio de tubérculos (Peixoto et al., 1996). Na cebola, contribui marcadamente para a melhoria da produção (Wiedenfeld \& Braverman, 1991). Em cenoura, eleva a produção de raízes (Carnicelli et al., 2000). No morangueiro, proporciona aumento da porcentagem de frutos comercializáveis, do rendimento e do tamanho dos frutos (Albregts \& Chandler, 1993). No pimentão, eleva a produtividade (Fontes \& Monnerat, 1984). Em tomate, doses elevadas aumentam o número de frutos, mas reduzem o peso médio de frutos, sem alterar a produção (Santos et al., 2001).

No Brasil há poucas informações sobre o emprego do nitrogênio no feijão-vagem (Camargo, 1984; Tessarioli Neto \& Groppo, 1992; Filgueira, 2000). Esses autores recomendam o emprego de nitrogênio em adubação de cobertura em dose média de $60 \mathrm{~kg} / \mathrm{ha}$, parcelada em duas aplicações, aos 20 e 40 dias após a seme- adura. Nesse sentido, com este trabalho objetivou-se avaliar os efeitos de doses e formas de aplicação de nitrogênio sobre a característica e produção dessa hortaliça.

Foi instalado um experimento em Latossolo Vermelho-Amarelo, no Centro de Ciências Agrárias da Universidade Federal da Paraíba, no município de Areia (PB), entre abril a agosto de 2000. Utilizou-se o delineamento experimental de blocos casualizados em esquema fatorial $6 \times 2+1$, constituídos de seis doses de nitrogênio $(0,20,40,60,80$ e $100 \mathrm{~kg} / \mathrm{ha})$, duas formas de aplicação (no solo e via foliar) e um tratamentotestemunha (sem adubação), em quatro repetições. Pela análise química do solo, verificaram-se as seguinte características: $\mathrm{pH}=6,10 ; \mathrm{P}=88,7 \mathrm{mg} / \mathrm{dm}^{3} ; \mathrm{K}=153$ $\mathrm{mg} / \mathrm{dm}^{3} ; \quad \mathrm{Ca}^{+2}=2,60 \mathrm{cmolc} / \mathrm{dm}^{3} ; \quad \mathrm{Mg}^{+2}=1,40$ cmolc $/ \mathrm{dm}^{3}$ e matéria orgânica $=12,5 \mathrm{~g} / \mathrm{dm}^{3}$.

O solo foi preparado mediante aração, gradagem, confecções de leirões e abertura de covas. A adubação de plantio constou da aplicação de 150 $\mathrm{kg} / \mathrm{ha}$ de $\mathrm{P}_{2} \mathrm{O}_{5}, 60 \mathrm{~kg} / \mathrm{ha}$ de $\mathrm{K}_{2} \mathrm{O}$ e de 20 t/ha de esterco bovino, enquanto a adubação de cobertura constou do fornecimento das doses de nitrogênio (uréia) aplicadas no solo e via foliar (10 g de N/litro de água), parceladas aos 20 e 40 dias após a semeadura. As parcelas constaram de 40 plantas, espaçadas de $1,00 \mathrm{~m}$ entre fileiras e $0,50 \mathrm{~m}$ entre plantas, sendo 20 consideradas úteis.

O plantio foi realizado no início de abril pelo método de semeadura direta, colocando-se quatro sementes por cova da cultivar Macarrão Trepador, a partir de sementes comerciais produzidas pela Topseed. Aos 15 dias, realizou-se o desbaste, deixando-se duas plantas por cova, e a prática de tutoramento, pelo sistema de varas cruzadas, enquanto as colheitas, em número de cinco, foram efetuadas semanalmente a partir de 50 dias de idade.

Procurou-se manter as plantas sempre no limpo, por meio de capinas, com auxílio de enxadas para evitar concorrência com as plantas daninhas e foram efetuadas irrigações pelo método de aspersão, no período de ausência de precipitação. Realizou-se controle fitossanitário, por meio da aplicação de Benomyl, para controlar mancha-de-alternaria (Alternaria alternata) ferrugem (Uromyces appendiculatus) e mancha-angular (Phaeoisariopsis griseola).

Foram obtidos dados de precocidade (número de dias da semeadura à antese das primeiras flores), de produtividade de vagens, obtida pelo somatório da produção das colheitas, transformado em toneladas de va- 
gens/ha, e da porcentagem de fibras das vagens, conforme a metodologia descrita por Silva (1990).

Os dados obtidos foram submetidos à análise de variância, utilizando-se o "software" SAEG (2000), com desdobramento da soma de quadrado da interação (doses e formas de aplicação) independente de sua significância. Dentro de cada forma de aplicação, foram testados diversos modelos polinomiais para os efeitos de doses. O critério para escolha do modelo foi a significância pelo teste $\mathrm{F}$ a $5 \%$ de probabilidade e que tenha apresentado o maior valor de coeficiente de determinação $\left(\mathrm{R}^{2}\right)$.

A partir das equações de segundo grau ajustadas, calcularam-se as doses de nitrogênio aplicadas no solo e via foliar que proporcionaram produtividades máximas econômicas. Entretanto, a fim de atenuar os problemas de variação cambial, para as formas de aplicação de nitrogênio que permitiram o cálculo da dose mais econômica, trabalhou-se com uma relação de troca, em vez de moeda corrente, igualando-se a derivada segunda às relações entre preços do produto e do insumo (Raij, 1991; Natale et al., 1996), vigentes em AreiaPB, em 2000, buscando-se, assim, dados mais estáveis. Neste estudo, os valores utilizados para as varáveis vagens e nitrogênio foram: $\mathrm{R} \$ 0,40 / \mathrm{kg}$ de vagens, $\mathrm{R} \$$ 0,70/kg de uréia. Dessa maneira, a 'moeda' utilizada nos cálculos da dose econômica de nitrogênio foi a própria vagem. Assim, a relação de equivalência entre o quilograma de uréia e o quilograma de vagens foi igual a 1,75 , ressaltando, porém, que o preço do quilograma de vagens correspondeu ao utilizado pelo produtor e que essa relação de preços pode variar a cada ano, conforme a demanda e a oferta.

Os desdobramentos das interações revelaram efeito quadrático em função das doses de nitrogênio aplicadas no solo e via foliar para a precocidade e a produtividade de vagens, ao passo que para o teor de fibra nas vagens apenas para as doses de nitrogênio aplicadas no solo.

Precocidade - O número de dias da antese deve ser entendido como o intervalo entre a semeadura e o inicio da floração, podendo ser empregado para estimar a precocidade de uma cultivar de feijão-vagem (Araújo, 2000). Nesse sentido, a testemunha proporcionou ao feijão-vagem maior precocidade, isso porque mais de $50 \%$ das plantas já apresentavam floração aos 35 dias. Quanto ao efeito do nitrogênio, as derivadas das equações de regressão permitiram calcular as doses de 21,31 e 19,55 kg/ha aplicadas, via foliar e no solo, como aquelas responsáveis por mais de 50\% das plantas com floração aos 36 e 37 dias (Figura 1). Possivelmente as doses de nitrogênio estimularam o crescimento, prolongando o período de crescimento das plan- tas, retardando a formação de frutos. No quiabeiro, o excesso de nitrogênio fornecido no inicio do crescimento retardou significativamente o florescimento, com repercussão negativa na produção de frutos (Zanin \& Mota, 1995).

$\mathrm{O}$ fato de a testemunha ter proporcionado plantas mais precoces permite deduzir que a precocidade do feijão-vagem não está relacionada com o nitrogênio, e sim, com as características genotípicas e, provavelmente, com outros elementos minerais não-mensurados. Hamasaki et al. (1998) e Andrade (1999) verificaram alterações na precocidade de genótipos de feijãovagem, sob condições de nutrição mineral balanceada.

Produtividade de vagens - A produtividade de vagens atingiu valores máximos estimados, 29 e $28 \mathrm{t} / \mathrm{ha}$ nas doses de 54 e $55 \mathrm{~kg} / \mathrm{ha}$ de nitrogênio aplicadas no solo e via foliar, respectivamente, enquanto a produtividade média obtida na testemunha foi de 19,6 t/ha (Figura 2). Embora as doses de nitrogênio responsáveis pelas produtividades máximas apresentem valores praticamente iguais, o nitrogênio fornecido no solo foi mais eficiente para o feijão-vagem expressar sua capacidade máxima de rendimento de vagens, possivelmente pela redução na sua perda. As perdas por volatilização de amônia proveniente da uréia podem ser drasticamente reduzidas, se o fertilizante for incorporado no solo, seguido de irrigação (Ribeiro, 1996). No feijão-comum, Almeida et al. (1999) observaram aumento de produtividade quando o nitrogênio foi fornecido diretamente no solo.

A produtividade média nacional de vagens para cultivares de feijão-vagem com hábito de crescimento indeterminado é de 25 t/ha (Tessarioli Neto \& Groppo, 1992; Blanco et al., 1997), portanto, a produtividade máxima obtida em função do nitrogênio aplicado no solo foi superior à média nacional em 4,0 t/ha, enquanto na adubação de nitrogênio fornecido via foliar, esse incremento foi de 3,0 t/ha. A produtividade alcançada pela testemunha (19,6 t/ha) foi inferior em 5,4; 9,4 e 8,4 t/ha em relação à média nacional, ao nitrogênio aplicado no solo e via foliar, respectivamente.

Provavelmente as doses nitrogênio responsáveis pelas máximas produtividades, juntamente com os nutrientes contidos no solo, supriram de forma equilibrada o feijãovagem. O equilíbrio entre os elementos nutritivos proporciona maiores produtividades do que maiores quantidades de macronutrientes isoladamente. Algumas hortaliças, tais como: alho (Resende \& Souza, 2000), cebola (Vidigal et al., 2000), cenoura (Carnicelli et al., 2000), quiabo (Zanin \& Mota 1995), melão (Faria et al., 1994) e tomate (Pinto et al., 1997) também tiveram seus rendimentos elevados, em função da aplicação de nitrogênio. 


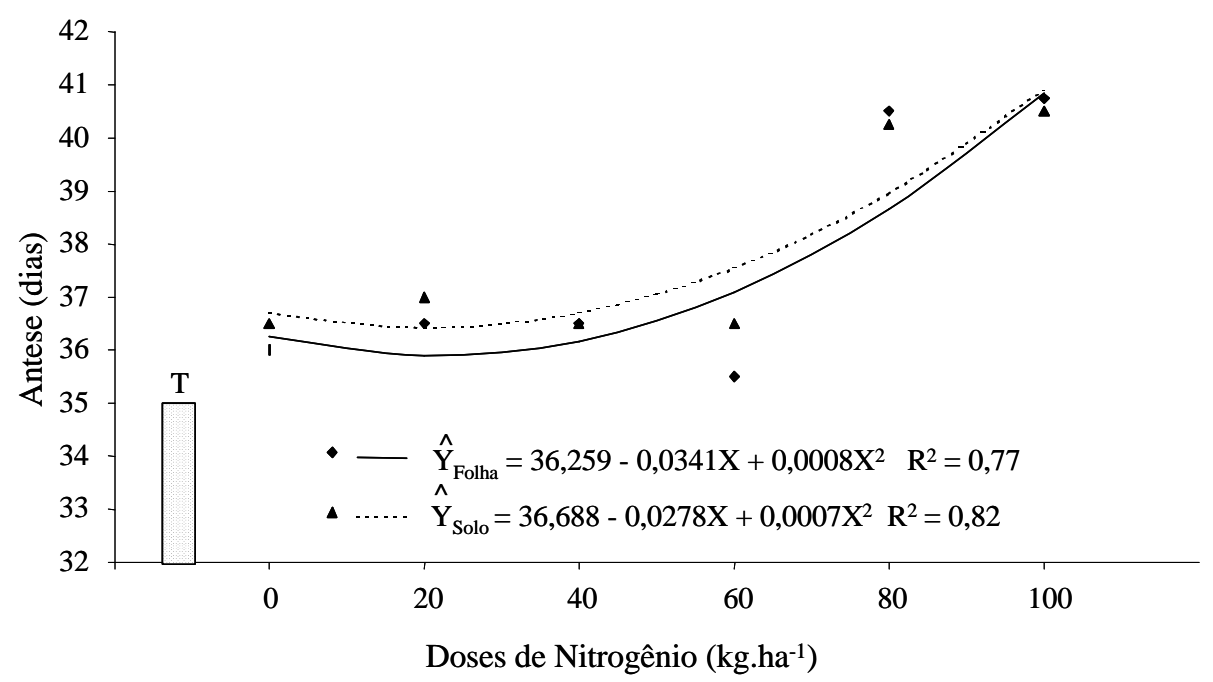

FIGURA 1 - Número de dias da antese, em feijão-vagem, cultivar Macarrão Trepador Topseed, em função de doses e formas de aplicação de nitrogênio. Areia, CCA-UFPB, 2000.

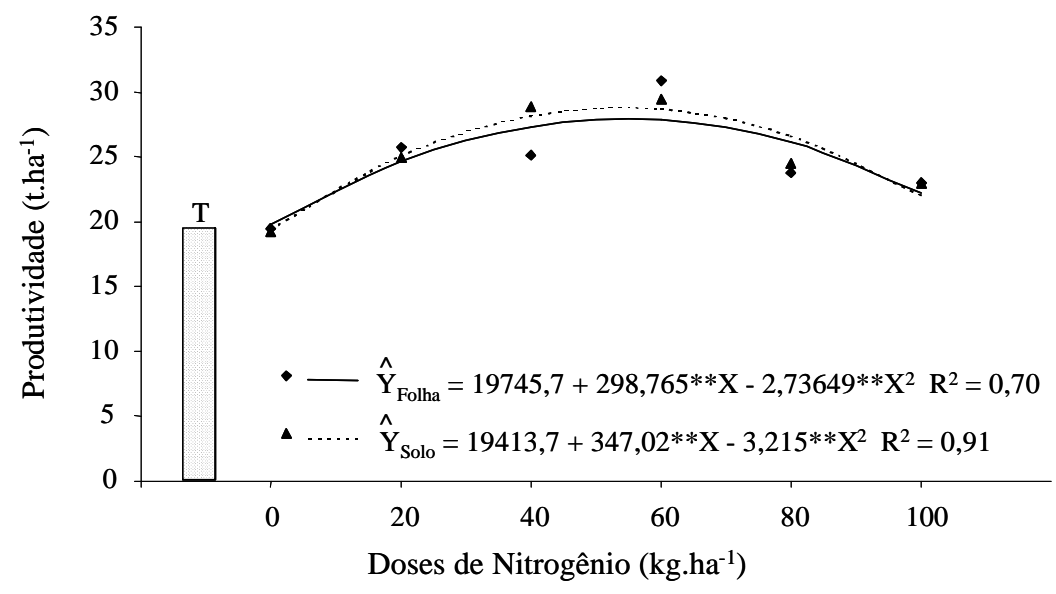

FIGURA 2 - Produtividade de vagem, em feijão-vagem, cultivar Macarrão Trepador Topseed, em função de doses e formas de aplicação de nitrogênio. Areia, CCA-UFPB, 2000.

A redução na produtividade verificada nas doses acima de 54 e $55 \mathrm{~kg} / \mathrm{ha}$ de nitrogênio aplicadas no solo e via foliar, respectivamente, pode indicar que seu excesso foi prejudicial ao desenvolvimento do feijãovagem, possivelmente em consequiência direta do efeito tóxico do amônio e da baixa taxa de nitrificação ou devido ao efeito indireto do amônio, reduzindo a absorção de outros cátions, isto é, exercendo forte efeito competi- tivo sobre os cátions $\left(\mathrm{K},{ }^{+} \mathrm{Ca}^{++}\right.$e $\left.\mathrm{Mg}^{++}\right)$, de tal forma que a absorção desses seriam reduzidas pela planta (Carnicelli et al., 2000). Huett (1989) verificou redução de produtividade em varias hortaliças, em função de doses elevadas de nitrogênio. Também, segundo Mengel \& Kirkby (1987), plantas deficientes em nitrogênio amadurecem precocemente, e o estádio de crescimento vegetativo é freqüentemente encurtado, já o execesso de 
nitrogênio, segundo Malavolta (1980), provoca aumento na duração do estádio vegetativo e queda de produção.

A recomendação média para aplicação de nitrogênio no feijão-vagem é de aproximadamente $60 \mathrm{~kg} / \mathrm{ha}$ para as Regiões Sul e Sudeste (Tessarioli \& Groppo, 1992; Filgueira, 2000). Nesse sentido, observa-se que as doses responsáveis pelas produtividades máximas do feijão-vagem apresentaram valores abaixo dessa recomendação, demonstrando que nas condições de Areia$\mathrm{PB}$, o nitrogênio deve ser fornecido ao feijão-vagem diretamente no solo, em dose de $54 \mathrm{~kg} / \mathrm{ha}$.

Teor de fibra nas vagens - A derivada da equação de regressão revelou a dose de $44 \mathrm{~kg} / \mathrm{ha}$ de nitrogênio aplicada no solo como aquela responsável pelo menor percentual de fibra nas vagens $(1,0 \%)$, ocorrendo maiores percentuais na ausência $(1,40 \%)$ e na dose máxima de nitrogênio $(1,52 \%$,$) . Quando o nitrogênio foi$ aplicado via foliar, as doses não promoveram alterações significativas, proporcionando um percentual médio de $1,36 \%$, enquanto a testemunha propiciou a produção de vagens com 1,48\% de fibra bruta (Figura 3).

$\mathrm{O}$ teor de fibra nas vagens estabelecido para a espécie está entre 0,70 a 1,70\% (Peixoto et al., 1993). Portanto, as doses de nitrogênio avaliadas, independentemente da forma de aplicação, não proporcionaram elevação no teor de fibra no feijão-vagem, cultivar Macarrão Trepador Topseed, além do padrão estabelecido para a espécie. Na mesma cultivar, Araújo (2000), empregando esterco suíno e adubação mineral, não verifi- cou teor de fibra nas vagens fora do padrão estabelecido para a espécie, enquanto Santos (1999), empregando esterco bovino, de caprino, de galinha e húmus de minhoca, no cultivo de feijão-vagem, utilizando a mesma cultivar empregada nesta pesquisa, verificou teores de fibra nas vagens variando de 0,90 a 3,3\%.

Análise econômica - Analisando-se economicamente os resultados, a dose mais econômica de nitrogênio aplicado no solo e via foliar foi de 53,7 e 54,4 $\mathrm{kg} / \mathrm{ha}$, resultando num rendimento estimado de 28,8 e 27,9 t/ha de vagens, respectivamente. A receita prevista, devido à aplicação do nitrogênio no solo e via foliar, pode ser calculada pelo aumento de produção proporcionada pelas doses econômicas, custo do fertilizante e pela receita obtida. Igualando-se a derivada primeira a zero, pode-se calcular o aumento de produção proporcionado por essas doses de nitrogênio. $O$ nitrogênio aplicado no solo proporcionou um aumento de 9,4 t/ha e, aplicado via foliar, de 8,1 t/ha de vagens. Deduzindo-se o custo de aquisição de $53,7 \mathrm{~kg}$ de nitrogênio, equivalente a $112 \mathrm{~kg}$ de uréia $(208 \mathrm{~kg}$ de vagens) e de $54,4 \mathrm{~kg}$ de nitrogênio, equivalente a $119 \mathrm{~kg}$ de uréia ( $212 \mathrm{~kg}$ de vagens), obteve-se um receita prevista de 9.115 e $7.988 \mathrm{~kg} / \mathrm{ha}$ de vagens, para o nitrogênio aplicado no solo e via foliar, respectivamente. Observa-se que as doses mais econômicas de nitrogênio estiveram próximas daquelas responsáveis pelos rendimentos máximos, e sob o ponto de vista de rendimento, proporcionaram rendimentos de vagens acima da média nacional.

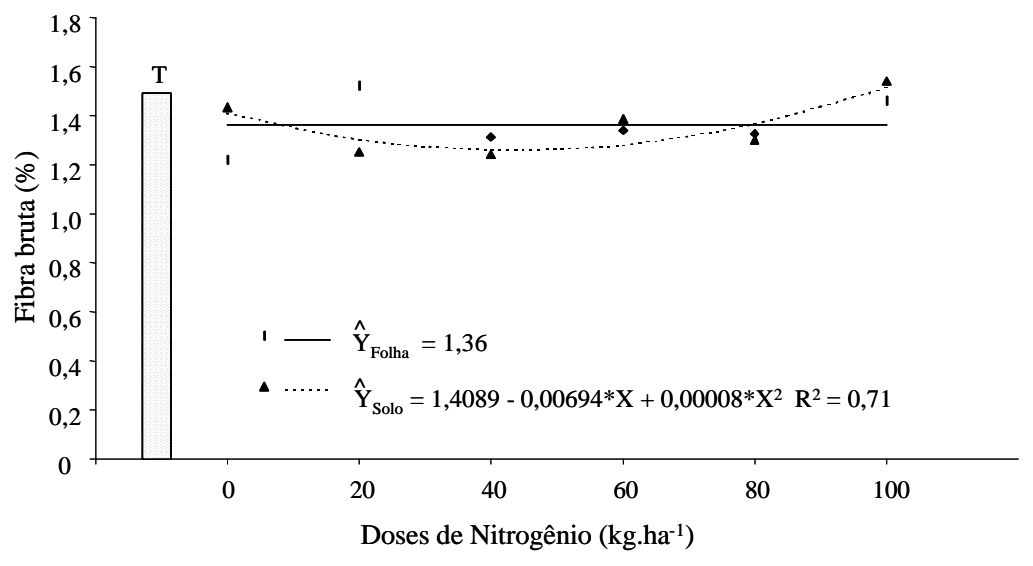

FIGURA 3 - Teor de fibra bruta, em vagens de feijão-vagem, cultivar Macarrão Trepador Topseed, em função de doses e formas de aplicação de nitrogênio. Areia, CCA-UFPB, 2000. 


\section{REFERÊNCIAS BIBLIOGRÁFICAS}

ALBREGTS, E. E.; CHANDLER, C. K. Slow release fertilizer rates for strawberry fruit production. Proceedings of the Florida State Horticultural Society, Tallahasse, v. 106, p. 187-189, 1993.

ALMEIDA, D. de; CARVALHO, M. A. C.; SÁ, M. E.; BUZETTI, S. Adubação nitrogenada em cobertura e via foliar em feijoeiro. In REUNIÃO NACIONAL DE FEIJÃO, 6., 1999, Salvador. Anais... Salvador: [s.n.], 1999. p. 737-740.

ALVARENGA, M. A. R.; SILVA, E. C. da; SOUZA, R. J. de; CARVALHO, J. G. de. Crescimento, teor e acúmulo de macronutrientes em alface americana sob doses de nitrogênio aplicados no solo e de níveis de cálcio aplicados via foliar. Horticultura Brasileira, Brasília, v. 18, p. 803-804, jul. 2000. Suplemento.

ANDRADE, A. C. de. Avaliação de linhagens e cultivares de feijão-vagem (Phaseolus vulgaris $L$.), nas condições de Areia-PB. João Pessoa: CCA-UFPB, 1999. 39 p.

ARAÚJO, J. S. Produção e qualidade de feijãovagem adubado com esterco suíno e fertilizante mineral. 2000. 74 p. Dissertação (Mestrado em Produção Vegetal) - Universidade Federal da Paraíba, Areia.

ATHANÁSIO, J. C. Adubação de feijão-vagem. In: SIMPOSIO SOBRE NUTRIÇAO E ADUBAÇAO DE HORTALIÇAS, 1990, Jaboticabal. Anais... Piracicaba: POTAFOS, 1993. p. 213-218.

BLANCO, M. C. S. G.; GROPPO, G. A.; TESSARIOLI NETO, J. Feijão-vagem (Phaseolus vulgaris L.). Manual Técnico das Culturas, Campinas, $\mathrm{n}$. 8, p. 63-65, 1997.

CAMARGO, L. de S. As hortaliças e seu cultivo. Campinas: Fundação Cargil, 1984.

CARNICELLI, J. H. de; PEREIRA, P. R. G.; FONTES, P. C. R.; CAMARGOS, M. I. de. Índices de nitrogênio na planta relacionados com a produção comercial de cenoura. Horticultura Brasileira, Brasília, v. 18, p. 808-810, jul. 2000. Suplemento.

FARIA, C. M. B. de; PEREIRA, J. R.; POSSÍDEO, E. L. de. Adubação orgânica e mineral na cultura do melão em um solo vertissolo do submédio São Francisco.
Pesquisa Agropecuária Brasileira, Brasília, v. 29, n. 2, p. 191-197, 1994.

FILGUEIRA, F. A. R. Novo manual de olericultura: agrotecnologia moderna na produção e comercialização de hortaliças. Viçosa: UFV, 2000. 402 p.

FONTES, P. C. R.; MONNERAT, P. H. Nutrição mineral e adubação das culturas de pimentão e pimenta. Informe Agropecuário, Belo Horizonte, v. 10, n. 113, p. 25-31, 1984.

HAMASAKI, R. I.; BRAZ, L. T.; PURQUERIO, L. F. V.; PEIXOTO, N. Comportamento de novas cultivares de feijão-vagem em Jaboticabal-SP. In: CONGRESSO BRASILEIRO DE OLERICULTURA, 38., 1998, Petrolina. Anais... Petrolina: SOB, 1998.

HUETT, D. O. Effect of nitrogen on the yield and quality of vegetables. Acta Horticulture, [S.1.], v. 247, p. 205-209, 1989.

MALAVOLTA, E. Elementos de nutrição mineral de plantas. São Paulo: CERES, 1980. 254 p.

MALAVOLTA, E. Manual de química agrícola: adubos e adubação. São Paulo: CERES, 1981. 596 p.

MALAVOLTA, E. Pesquisa com nitrogênio no Brasil: passado, presente e perspectivas. In: SIMPÓSIO BRASILEIRO SOBRE NITROGÊNIO EM PLANTAS, 1., 1990, Itaguaí. Anais... Itaguaí: Sociedade Brasileira de Fisiologia Vegetal, 1990. p. 89-177.

MENGEL, K.; KIRKBY, E. A. Principles of Plant Nutrition. Bern: International Potash Institute, 1987. 687 p.

NATALE, W.; COUTINHO, E. L. M.; BOARETTO, A.; PEREIRA, F. M. Dose mais econômica de adubo nitrogenado para a goiabeira em formação. Horticultura Brasileira, Brasília, v. 14, n. 2, p. 196-199, 1996.

PEIXOTO, J. R.; GARCIA, C. A. P.; MARTINS, J. F. Produtividade de batata cv. Achat em função de doses de NPK e B. Horticultura Brasileira, Brasília, v. 14, n. 2, p. 232-235, 1996.

PEIXOTO, N.; SILVA, L. O.; THUNG, M. D. T.; SANTOS, G. Produção de sementes de linhagens e cultivares arbustivas de feijão-vagem em Anápolis. Horticultura Brasileira, Brasília, v. 11, n. 2, p. 151-152, 1993. 
PINTO, J. M.; SOARES, J. M.; COSTA, N. D.; FARIA, C. M. de; BRITO, L. T. de L.; SILVA, D. J. Doses e períodos de aplicação de nitrogênio via água de irrigação na cultura do tomate. Horticultura Brasileira, Brasília, v. 15, p. 15-18, maio, 1997.

RAIJ, B. Van. Fertilidade do solo e adubação. Piracicaba: Ceres/Potafos, 1991. 343 p.

RESENDE, G. M. de.; SOUZA, R. J. de. Doses e épocas de aplicação de nitrogênio sobre a produtividade e características comerciais do alho. Horticultura Brasileira, Brasília, v. 18, p. 759-760, Jul. 2000. Suplemento.

RIBEIRO, A. C. Como evitar a perda do nitrogênio de adubos por volatização. Boletim informativo da SBCS, Campinas, v. 21, n. 2, p. 43-46, 1996.

SAEG. Sistema para análise estatística: versão 8.0. Viçosa: Fundação Artur Bernardes, 2000.

SANTOS, G. M. Rendimento e qualidade de feijãovagem (Phaseolus vulgaris $L$.) em função de fontes e doses de matéria orgânica. 1999. 91 p. Dissertação (Mestrado em Produção Vegetal) - Universidade Federal da Paraíba, Areia.
SANTOS, P. R.; PEREIRA, A. S.; FREIRE, C. J. Cultivar e adubação NPK na produção de tomate salada. Horticultura Brasileira, Brasília, v. 19, n. 1, p. 35, 2001.

SILVA, D. J. Análise de alimentos: métodos químicos e biológicos. 2. ed. [S.1.: s.n.], 1990. 165 p.

TESSARIOLI NETO, J.; GROPPO, G. A. A cultura do fejão-vagem. Boletim técnico CATI, Campinas, $n$. 212, p. 1-12, 1992.

VIDIGAL, S. M.; PEREIRA, P. R. G.; SEDIYAMA, C. S.; SEDIYAMA, M. A. N.; FONTES, P. C. R. Produção de cebola influenciada por doses, fontes e parcelamento de nitrogênio em diferentes épocas de cultivo de verão. Horticultura Brasileira, Brasília, v. 18, p. 814815, Jul. 2000.

WIEDENFELD, R.; BRAVERMAN, M. Fertilizer nitrogen sources for vegetable production. Subtropical Plant Science, [S.1.], v. 44, p. 33, 1991.

ZANIN, A. C. W.; MOTA, I. F. Efeito de fontes e épocas de aplicação de nitrogênio na produção e qualidade de sementes de quiabeiro. Horticultura Brasileira, Brasília, v. 13, n. 2, p. 167-172, 1995. 